\title{
Connectionist Models of Cognition and Perception II
}




\title{
ROGRESS IN NEURAL PROCESSING*
}

\author{
eries Advisor
}

lan Murray (University of Edinburgh)

Jol. 3: Parallel Implementation of Backpropagation Neural Networks on Transputers: A Study of Training Set Parallelism

by P. Saratchandran, N. Sundararajan \& S.-K. Foo

Vol. 4: Analogue Imprecision in MLP Training

by Peter J. Edwards \& Alan F. Murray

Vol. 5: Applications of Neural Networks in Environment, Energy, and Health Eds. Paul E. Keller, Sherif Hashem, Lars J. Kangas E Richard T. Kouzes

Vol. 6: Neural Modeling of Brain and Cognitive Disorders

Eds. James A. Reggia, Eytan Ruppin \& Rita Sloan Berndt

Vol. 7: Decision Technologies for Financial Engineering

Eds. Andreas S. Weigend, Yaser Abu-Mostafa \& A.-Paul N. Refenes

Vol. 8: Neural Networks: Best Practice in Europe

Eds. Bert Kappen \& Stan Gielen

Vol. 9: RAM-Based Neural Networks

Ed. James Austin

Vol. 10: Neuromorphic Systems: Engineering Silicon from Neurobiology Eds. Leslie S. Smith \& Alister Hamilton

Vol. 11: Radial Basis Function Neural Networks with Sequential Learning Eds. N. Sundararajan, P. Saratchandran \& Y.-W. Lu

Vol. 12: Disorder Versus Order in Brain Function: Essays in Theoretical Neurobiology

Eds. P. Arhem, C. Blomberg \& H. Liljenström

Vol. 13: Business Applications of Neural Networks: The State-of-the-Art of Real-World Applications

Eds. Paulo J. G. Lisboa, Bill Edisbury \& Alfredo Vellido

Vol. 14: Connectionist Models of Cognition and Perception

Eds. John A. Bullinaria \& Will Lowe

*For the complete list of titles in this series, please write to the Publisher. 
Proceedings of the Eighth Neural Computation and Psychology Workshop

\section{Connectionist Models of Cognition and Perception II}

University of Kent, UK $\quad 28-30$ August 2003

Editors

Howard Bowman

University of Kent, UK

Christophe Labiouse

University of Liege, Belgium 
Published by

World Scientific Publishing Co. Pte. Ltd.

5 Toh Tuck Link, Singapore 596224

USA office: Suite 202, 1060 Main Street, River Edge, NJ 07661

UK office: 57 Shelton Street, Covent Garden, London WC2H 9HE

\title{
British Library Cataloguing-in-Publication Data
}

A catalogue record for this book is available from the British Library.

\author{
CONNECTIONIST MODELS OF COGNITION, PERCEPTION AND EMOTION \\ Proceedings of the Eighth Neural Computation and Psychology Workshop \\ Copyright $\odot 2004$ by World Scientific Publishing Co. Pte. Ltd. \\ All rights reserved. This book, or parts thereof, may not be reproduced in any form or by any means, \\ electronic or mechanical, including photocopying, recording or any information storage and retrieval \\ system now known or to be invented, without written permission from the Publisher.
}

For photocopying of material in this volume, please pay a copying fee through the Copyright Clearance Center, Inc., 222 Rosewood Drive, Danvers, MA 01923, USA. In this case permission to photocopy is not required from the publisher.

ISBN $981-238-805-2$ 


\section{Preface}

This volume collects together refereed versions of papers presented at the Eighth Neural Computation and Psychology Workshop (NCPW 8), which was held at the University of Kent at Canterbury, England in August 2003. The NCPW series is a well-established and lively forum that brings together researchers from such diverse disciplines as artificial intelligence, cognitive science, computer science, neuroscience, philosophy and psychology. Thirty-five papers were presented at the event, of which eight were invited papers. More than fifty participants attended the workshop that drew researchers from England, Ireland, the Netherlands, Belgium, France, Israel, Spain, Finland, Germany, and the United States. This large and cosmopolitan audience is evidence of the ever-increasing importance of neural network modelling in the cognitive sciences at the dawn of the twenty-first century. The overarching theme of this eighth workshop in the series was Connectionist Models of Cognition and Perception.

The structure of this book broadly follows the session structure of the event, although some papers have been repositioned in order to increase the coherence of the publication. The book is divided into nine sections, which cross the spectrum of cognitive phenomena and reflect the extent of research being undertaken on connectionist modelling of cognition. Specifically, the book contains sections on Memory, Vision, Action and Navigation, Developmental Processes, Category Acquisition, Attention, High Level Cognition and Implementation Issues, Language and Speech, and Cognitive Architectures and Binding.

The Memory section contains two papers. Davelaar and Usher present a model of active maintenance in working memory and their computational model sheds light on the distinction between short-term and long-term memories. Musca, Rousset and Ans investigate the effect of material structure on retroactive and proactive interference. They propose a dual-network architecture to account for these effects in association learning. The Vision section is also comprised of two papers. Firstly, Hurri, Vayrnynen and Hyarinen consider the spatio-temporal properties of simple-cells in V1 based on their temporal coherence and 
with the help of independent component analysis. Then Karanka and Luque explore how a simple-recurrent network can be used to predict time-to-collision.

The next section is devoted to Action and Navigation. Of the four papers in this section, the first (by Theofilou, Destrebecqz and Cleeremans) uses forward models to explore human's ability to learn sequences. The second paper in the section, which is by Richardson, Davey, Peters and Done, considers how human character production can be modelled using recurrent neural networks. Then, Girard, Filliat, Meyer, Berthoz and Guillot explore basal ganglia-based control architectures, which enable robots to select actions and navigate. The final paper in this section (by Schenck and Moller) presents a system that can learn saccadic eye movements in a staged manner.

Developmental Processes are considered in the next section, which comprises three papers. The first paper is by Westermann and Mareschal who provide a RBF-like neural network account for an observed asymmetry that occurs in the categorization of cats and dogs by 3-4 month old children. Then Carlson and Triesch use reinforcement learning to provide a nurture-based explanation of the emergence of gaze following during infant development. Finally, Levy's paper, which concludes this section, reviews the ways in which connectionist models have been used to explain autism.

Next we come to a section focused on Category Acquisition. The initial paper in this section is by Joyce and Cottrell and it provides a connectionist explanation for why and how a brain area specifically dedicated to expert discrimination may have developed. Then Fink, Ben-Shakhar and Horn use a neural network to contrast the role of two factors that govern feature creation: the informative value and the degree of parsimony of the feature set. Finally, Mermillod, Guyader and Chauvin answer the question of whether the energy spectrum of Gabor wavelets can represent sufficient information for recognition and classification tasks.

The next section is devoted to neural network models of attentional processes. Taylor approaches the issue of consciousness through the provision of an engineering control account of attention and motor control. Then Heinke, Humphreys and Tweed present an extension of the Selective Attention for Identification network, which models visual search. Next, Bowman, Wyble and Barnard, present a neural network model of the deployment of attention over time, in the context 
of the attentional blink. The final paper of the section is by Bartos and it adds an attentional mechanism to the configural-cue model of stimulus representation.

High Level Cognition and Implementation Issues are considered in the next section, which begins with a paper by Leech, Mareschal and Cooper on the application of attractor networks to analogical reasoning. Then Bullinaria discusses a number of simulations that consider how irrational behaviour could emerge from evolution. Next, Van Overwalle explores how connectionism can be applied in the social psychological context of the multiple inference model of person impression formation. In the final paper in this section Connolly, Marian and Reilly present several algorithms for the simulation of spiking neural networks on single processor systems.

The penultimate section addresses Language and Speech, with the first paper (by Shillcock and Monaghan) considering visual word recognition using a split-fovea model. In the next paper, Hayes, Murphy, Davey and Smith use simple recurrent networks to provide a nurturebased explanation of the formation of English noun-noun plurals. Then Moscoso del Prado Martin, Schreuder and Baayen consider how to build distributed representations of word forms by accumulation of expectations. Finally, Hammerton compares connectionist models of speech segmentation in the context of the utterance boundary strategy.

The last section of the book focuses on Cognitive Architectures and Binding. Firstly, Borisyuk and Kazanovich present an oscillation-based cognitive model of brain function and then Mair, Shepperd, Cartwright, Kirsopp, Premraj and Heathcote present experimental findings on object feature binding and then discuss how these findings could be implemented in a neural network.

We would like to thank all those that attended NCPW' 8 and made the event such a stimulating occasion. We would particularly like to thank our eight invited speakers: John Bullinaria, Gary Cottrell, Bob French, Peter Hancock, Richard Shillcock, Chris Solomon, John Taylor and Marius Usher. All of whom gave thought-provoking talks which fully reflected the state of the art of research in their chosen area. We would especially like to pay thanks to Gary Cottrell, who despite heavy jet lag, enthusiastically contributed throughout the event, both intellectually and socially.

We would also like to thank the following for reviewing papers for the proceedings: Paul Bartos, Roman Borisyuk, John Bullinaria, Axel 
Cleeremans, Gary Cottrell, Eddy Davelaar, Michael Fink, Bob French, Benoit Girard, Peter Hancock, Dietmar Heinke, Jarmo Hurri, Robert Leech, Martin Le Voi, Joe Levy, Fermin Moscoso del Prado Martin, Martial Mermillod, Serban Musca, Ronan Reilly, Corina Sas, Wolfram Schenk, Richard Shillcock, Dionyssios Theofilou, Jochen Triesch, Marius Usher, Tim Valentine, Frank van Overwalle and Brad Wyble.

On the organisational side, we would like to pay special thanks to Jenny Oatley and Deborah Sowrey who provided excellent secretarial support before, after and during the event. In addition, Colin Johnson, Miguel Mendao, Vikki Roberts and Brad Wyble freely gave of their time in order to provide organisational support for the event. Finally, we wish to thank the Computing Laboratory at the University of Kent at Canterbury, which provided considerable financial support for the event.

Howard Bowman \& Christophe Labiouse ${ }^{1}$

December 2003

${ }^{1}$ Christophe Labiouse is a Research Fellow of the Belgian National Fund of Scientific Research (FNRS). 


\section{Contents}

Preface $\quad v$

\section{Memory}

An Extended Buffer Model for Active Maintenance and

Selective Updating

Eddy J. Davelaar and Marius Usher

Effects of the Learning Material Structure on Retroactive and

Proactive Interference in Humans: When the Self-Refreshing

Neural Network Mechanism Provides New Insights

Serban C. Musca, Stephane Rousset and Bernard Ans

\section{Vision}

Spatiotemporal Linear Simple-Cell Models Based on Temporal Coherence and Independent Component Analysis

Jarmo Hurri, Jaakko Vayrynen and Aapo Hyvärinen

Predicting Collision: A Connectionist Model

Joni Karanka and David Luque

\section{Action and Navigation}

Applying Forward Models to Sequence Learning:

A Connectionist Implementation

Dionyssios Theofilou, Arnaud Destrebecqz

and Axel Cleeremans

The Simulation of Character Production Behaviours in

Fiona Richardson, Neil Davey, Lorna Peters and John Done

An Integration of Two Control Architectures of Action Selection and Navigation Inspired by Neural Circuits in the Vertebrate:

The Basal Ganglia

Benoit Girard, David Filliat, Jean-Arcady Meyer,

Alain Berthoz and Agnès Guillot 
Staged Learning of Saccadic Eye Movements with a Robot

Camera Head

Wolfram Schenck and Ralf Möller

\section{Developmental Processes}

Modelling Asymmetric Infant Categorization with the

Representational Acuity Hypothesis

Gert Westermann and Denis Mareschal

A Computational Model of the Emergence of Gaze Following

Eric Carlson and Jochen Triesch

Connectionist Models of Over-Specific Learning in Autism

Joseph P. Levy

\section{Category Acquisition}

Solving the Visual Expertise Mystery

Carrie A. Joyce and Gary W. Cottrell

Empirical Evidence and Theoretical Analysis of Feature Creation

During Category Acquisition

Michael Fink, Gershon Ben-Shakhar and David Horn

Does the Energy Spectrum from Gabor Wavelet Filtering Represent

Sufficient Information for Neural Network Recognition and

Classification Tasks?

Martial Mermillod, Nathalie Guyader and Alan Chauvin

\section{Attention}

Through Attention to Consciousness by CODAM John G. Taylor

Modeling Visual Search: Evolving the Selective Attention for Identification Model (SAIM)

Dietmar Heinke, Glyn W. Humphreys and Claire L. Tweed

Towards a Neural Network Model of the Attentional Blink

Howard Bowman, Brad P. Wyble and Phil J. Barnard

Limited Capacity Dimensional Attention and the Configural-Cue Model of Stimulus Representation 


\section{High Level Cognition and Implementation Issues}

A Temporal Attractor Framework for the Development of Analogical Completion

Robert Leech, Denis Mareschal and Richard Cooper

On the Evolution of Irrational Behaviour John A. Bullinaria

Multiple Person Inferences: A View of a Connectionist Integration Frank Van Overwalle

Approaches to Efficient Simulation with Spiking Neural Networks Colm G. Connolly, Ioana Marian and Ronan G. Reilly

\section{Language and Speech}

Reading, Sublexical Units and Scrambled Words: Capturing the Human Data

Richard C. Shillcock and Padraic Monaghan

How the Constraints on English Compound Production Might

Be Learnt from the Linguistic Input: Evidence from Simple

Recurrent Networks

Jenny A. Hayes, Victoria A. Murphy, Neil Davey

and Pam M. Smith

Using the Structure Found in Time: Building Distributed

Representations of Word Forms by Accumulation of Expectations

Fermin Moscoso del Prado Martin, Robert Schreuder and $R$. Harald Baayen

Connectionist Models of Speech Segmentation and the Utterance Boundary Strategy: A Comparison of the SOM, SRN and N-GRAMS

James A. Hammerton

\section{Cognitive Architectures and Binding}

Designing an Oscillatory Model of Brain Cognitive Functions

Roman Borisyuk and Yakov Kazanovich

Understanding Object Feature Binding Through Experimentation and as a Precursor to Modelling

Carolyn Mair, Martin Shepperd, Michelle Cartwright,

Colin Kirsopp, Rahul Premraj and David Heathcote 